\title{
Modeling Strategies for Enantiomers Separation by SMB Chromatography
}

\author{
Luís S. Pais, José M. Loureiro, and Alírio E. Rodrigues \\ Laboratory of Separation and Reaction Engineering, Faculty of Engineering, University of Porto, 4099 Porto Codex, Portugal
}

\begin{abstract}
Modeling strategies for simulated moving bed adsorbers were studied to compare the simulated moving bed model (SMB) that considers the real shift of the injection and collection points to the true moving bed approach (TMB) that considers liquid and solid flow in opposite directions. The prediction of these two models is compared in terms of steady-state performance, steady-state internal concentration profiles, and transient behavior of the extract and raffinate purities. The influence of the degree of subdivision of the bed in the SMB model predictions is also analyzed and compared with the $T M B$ performance. Model results are compared with experimental results obtained for the chromatographic separation of binaphthol enantiomers.
\end{abstract}

\section{Introduction}

The countercurrent chromatography concept introduced with the SMB technology by UOP (Broughton and Gerhold, 1961) has been recently applied in new areas such as biotechnology, pharmaceuticals, and fine chemistry. Pilot and industrial SMB for such applications have been developed by different companies (Nicoud, 1993, 1997; Gattuso et al., 1994, 1995). SMB chromatography is a suitable technique for pharmaceutical process development, offering many advantages over conventional preparative chromatography, leading to cleaner, smaller, safer and faster processes (Nicoud, 1997; Guest, 1997). The SMB technology has been applied only for the recovery of one species from a mixture or binary separations. However, it has some drawbacks related with the complexity of SMB design, its operation and optimization for each particular application (Zhong and Guiochon, 1997). Following this increasing interest, several works have been published reporting SMB applications from laboratory to industrial scale. Recent examples of resolution of enantiomers by SMB chromatography are presented in Table 1 showing the versatility of this technology.

The countercurrent contact between the fluid and solid phases used in the SMB chromatography maximizes the mass-transfer driving force, leading to a significant reduction in mobile and stationary phases consumption when compared with elution chromatography (Nicoud et al., 1992; Ballanec and Hotier, 1993; McCulloch et al., 1994). The concept of the

Correspondence concerning this article should be addressed to A. E. Rodrigues.
SMB is based in the TMB process, where liquid and solid flow in opposite directions (Figure 1). The liquid flowing out of section IV is recycled to section I, while the solid coming out of section I is recycled to section IV. The feed is continuously injected in the middle of the system and two product lines can be collected: the extract, rich in the compounds that are more retained and so preferentially carried with the solid phase, and the raffinate, rich in the less retained species that move upwards with the liquid phase. If liquid and solid flow rates are conveniently chosen, it is possible to recover continuously purified products, eliminating the drawback of dilution of species and low adsorbent utilization present in batch chromatography.

The SMB concept was introduced for practical reasons because of operating problems associated with the solid circulation in a TMB unit. In the SMB technology (Figure 2), the countercurrent movement of fluid and solid is simulated by an appropriate flow switching sequence. In fact, most of the benefits of a countercurrent operation can be achieved using an adsorbent bed divided into a number of fixed-bed columns, while the inlet (eluent and feed) and outlet lines (extract and raffinate) move simultaneously one column at fixed switch time intervals in the direction of the fluid phase flow.

Several authors have developed models to predict the performance of an SMB separation process with reasonable agreement with experimental results. These models can be classified according to the description of the fluid flow as continuous flow models (plug or axial dispersion flow) or as 
Table 1. Recent Examples of Resolution of Enantiomers by SMB Chromatography

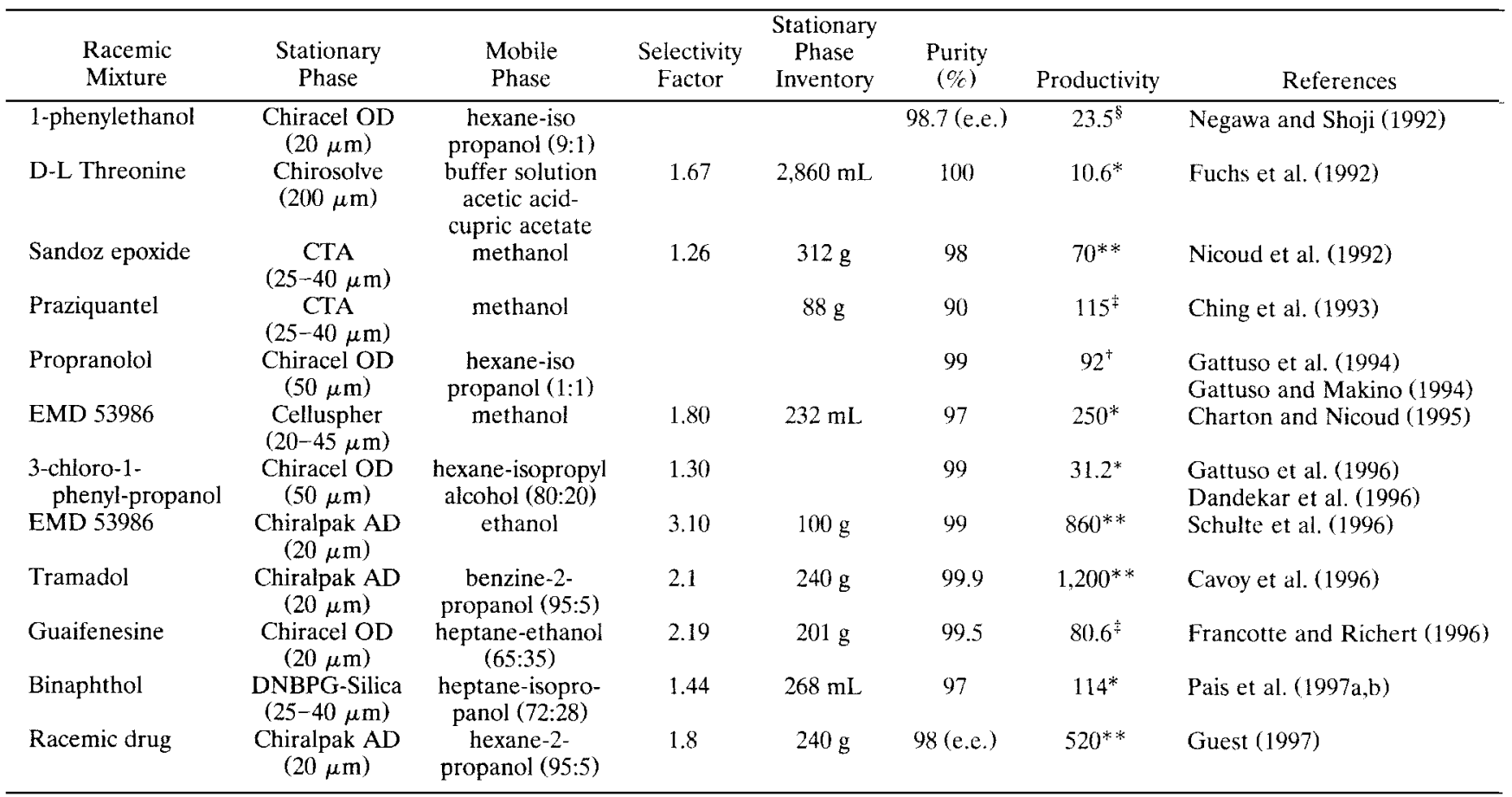

Productivity in: ${ }^{*} \mathrm{~g}$ feed/d $\mathrm{I}_{\mathrm{CSP}} ;{ }^{* *} \mathrm{~g}$ feed/d $\mathrm{kg}_{\mathrm{CSP}} ;{ }^{\dagger} \mathrm{g}$ product/d $\mathrm{l}_{\mathrm{CSP}} ;{ }^{+} \mathrm{g}$ product $/ \mathrm{d} \mathrm{kg}_{\mathrm{CSP}} ;{ }^{8} \mathrm{~g}$ product/d $\mathrm{I}_{\text {hed }}$.

mixing cell models. Otherwise, some authors considered the mass-transfer rate inside particles described by the linear driving force approximation, while others used the equilibrium theory and neglected mass-transfer resistances and axial mixing. Some references about the SMB modeling assuming the true moving bed equivalence can be found in Ruthven and Ching (1989) and Pais et al. (1997a). The modeling of an SMB taking into account its intermittent behavior was also carried out by some authors. Considering linear isotherms, the transient evolution of an SMB process was studied by Hidajat et al. (1986a), using the mixing cell model by Zhong and Guiochon (1996) and Yun et al. (1997) using the equilibrium-dispersion model, and by Hashimoto et al. (1983), Chu and Hashim (1995), and Hotier (1996), considering finite mass-transfer rates. The same study was developed for nonlinear multicomponent equilibria by Storti et al. (1988), Hassan et al. (1995), and Lim and Ching (1996). The effect of the subdivision of the adsorbent bed in the performance of an

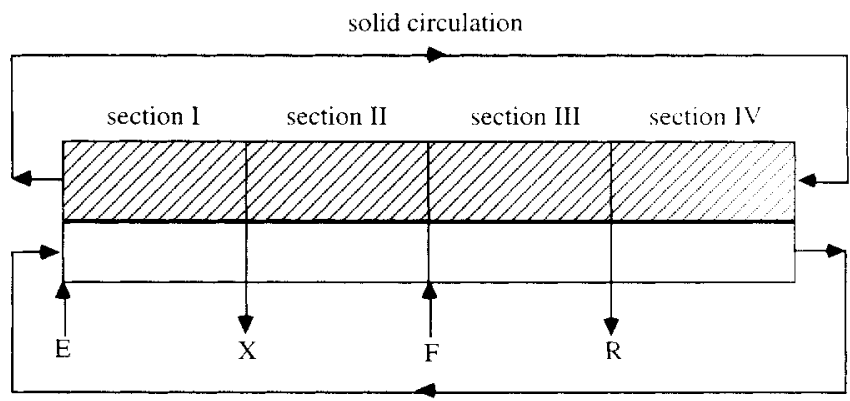

liquid recirculation

Figure 1. Four-section TMB.
SMB was also considered by Hidajat et al. (1986b), Storti et al. (1989a,b), and Bauer et al. (1996).

As was pointed out, there are two main strategies of mod eling an SMB process: one representing the real SMB, taking into account the periodic switch of the injection and collection points, and the other by assuming the equivalence with the TMB. This article addresses some questions concerning the equivalence between SMB and TMB strategies of modeling, namely:

- What is the "degree of equivalence" between SMB and TMB approaches? This question will be answered by looking

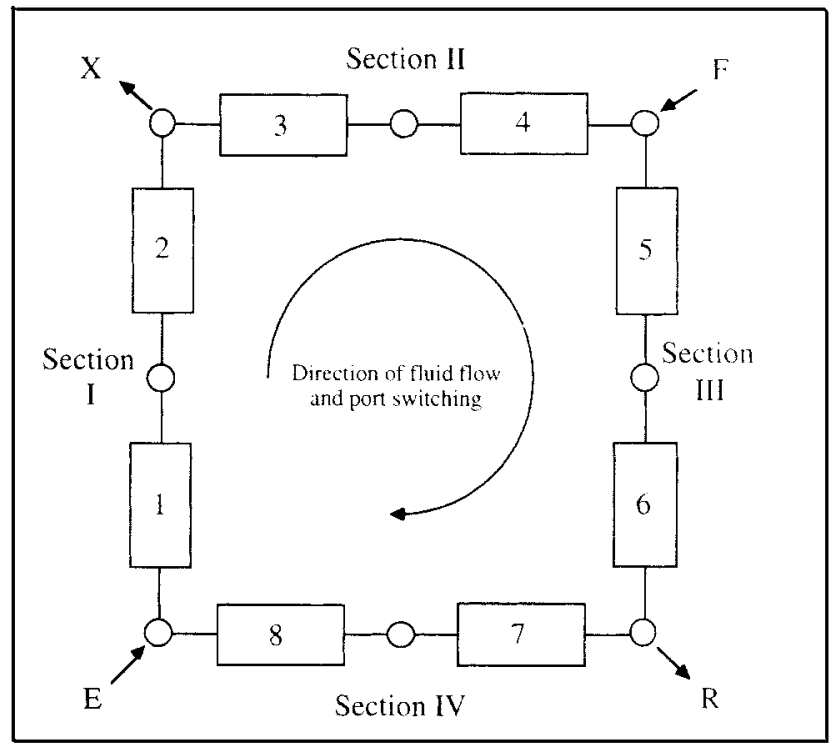

Figure 2. Four-section SMB. 
at steady-state internal concentration profiles for TMB and SMB; transient evolution of extract and raffinate purities predicted by SMB and TMB; influence of subdivision of the bed in the SMB operation, and which degree of subdivision is equivalent to TMB.

- Are both strategies equivalent in terms of process optimization, that is, the better choice of liquid and solid flow rates/switch time interval?

These questions are analyzed for the case of chromatographic resolution of binaphthol enantiomers and some of these aspects are compared with experimental results obtained in an SMB pilot plant.

\section{Simulated Moving Bed Strategies of Modeling SMB model}

The concept of the simulated moving bed is illustrated in Figure 2; the countercurrent motion of fluid and solid is simulated with a discrete jump of injection and collection points in the same direction of the fluid phase. The SMB system is then constituted by a set of identical fixed-bed columns, which are connected in series.

Model equations for the SMB model result from the mass balances over a volume element of the bed and inside the particle. Axial dispersion flow for the bulk fluid phase is included and the linear driving force approximation is used to describe the intraparticle mass-transfer rate. The model can handle any kind of adsorption equilibrium isotherm. Model equations for the transient SMB model are summarized below with initial and boundary conditions, as well as with the necessary mass balances at the nodes between each column.

\section{Model equations for the transient SMB}

Mass Balance in a Volume Element of the Bed $k$

$$
\frac{\partial c_{i k}}{\partial t}=D_{L_{k}} \frac{\partial^{2} c_{i k}}{\partial z^{2}}-v_{k}^{*} \frac{\partial c_{i k}}{\partial z}-\frac{(1-\epsilon)}{\epsilon} k\left(q_{i k}^{*}-q_{i k}\right)
$$

Mass Balance in the Particle

$$
\frac{\partial q_{i k}}{\partial t}=k\left(q_{i k}^{*}-q_{i k}\right)
$$

Initial Conditions

$$
t=0: \quad c_{i k}=q_{i k}=0
$$

Boundary Conditions for Column $k$

$$
z=0: \quad c_{i k}-\frac{D_{L_{k}}}{v_{k}^{*}} \frac{d c_{i k}}{d z}=c_{i k, 0}
$$

where $c_{i k, 0}$ is the inlet concentration of species $i$ in column $k$.

$z=L_{k}$

For a column inside a section and for extract and raffinate nodes

$$
c_{i k}=c_{i k+1,0}
$$

For the eluent node

$$
c_{i k}=\frac{v_{\mathrm{I}}^{*}}{v_{\mathrm{IV}}^{*}} c_{i k+1,0}
$$

For the feed node

$$
c_{i k}=\frac{v_{\mathrm{III}}^{*}}{v_{\mathrm{II}}^{*}} c_{i k+1,0}-\frac{v_{F}}{v_{\mathrm{II}}^{*}} c_{i}^{F}
$$

\section{Global Balances}

Eluent node

$$
v_{\mathrm{I}}^{*}=v_{\mathrm{IV}}^{*}+v_{E}
$$

Extract node

$$
v_{\mathrm{II}}^{*}=v_{\mathrm{I}}^{*}-v_{X}
$$

Feed node

$$
v_{\mathrm{III}}^{*}=v_{\mathrm{II}}^{*}+v_{F}
$$

Raffinate node

$$
v_{\mathrm{IV}}^{*}=v_{\mathrm{III}}^{*}-v_{R}
$$

\section{Multicomponent Adsorption Equilibrium Isotherm}

$$
q_{A k}^{*}=f_{A}\left(c_{A k}, c_{B k}\right) \quad \text { and } \quad q_{B k}^{*}=f_{B}\left(c_{A k}, c_{B k}\right)
$$

where $i=A, B$ refers to the species in the mixture, and $k=1$, $2, \ldots$, NCOL is the column number.

Due to the switch of inlet and outlet lines, each column plays different functions during a whole cycle, depending on its location (section). As a consequence, we shall notice that the boundary conditions for each column change after the end of each switch time interval. This time-dependence of the boundary conditions leads to a cyclic steady state for this system, instead of a real steady state present in the TMB model. This means that, after cyclic steady state is reached. the internal concentration profiles vary during a given cycle, but they are identical at the same time for two successive cycles.

\section{TMB model}

In the TMB model, the solid phase is assumed to move in plug flow in the opposite direction of the fluid phase, while the inlet and outlet lines remain fixed. As a consequence, each column plays the same function, depending on its location (Figure 1).

The equivalence between the TMB and the SMB models is made by keeping constant the liquid velocity relative to the solid velocity, that is, the liquid velocity in the TMB is $v_{j}=v_{j}^{*}$ $-u_{s}$, where $v_{j}^{*}$ and $v_{j}$ are the liquid velocities in the SMB and TMB, respectively, and $u_{s}$ is the solid velocity. Also, the solid velocity in the TMB model $u_{s}$ must be evaluated from 
the value of the switch time interval $t^{*}$ of the SMB model, as $u_{s}=L_{c} / t^{*}$, where $L_{c}$ is the length of one column. Alternatively, the equivalence can be made in terms of flow rates, $Q_{j}=Q_{j}^{*}-(\epsilon / 1-\epsilon) Q_{s}$ with $Q_{s}=(1-\epsilon) V_{c} / t^{*}$. The resulting model equations for the transient TMB are shown below.

\section{Model equations for the transient TMB}

Mass Balance in a Volume Element of the Bed $j$

$$
\frac{\partial c_{i j}}{\partial t}=D_{L_{j}} \frac{\partial^{2} c_{i j}}{\partial z^{2}}-v_{j} \frac{\partial c_{i j}}{\partial z}-\frac{(1-\epsilon)}{\epsilon} k\left(q_{i j}^{*}-q_{i j}\right)
$$

Mass Balance in the Particle

$$
\frac{\partial q_{i j}}{\partial t}=u_{s} \frac{\partial q_{i j}}{\partial z}+k\left(q_{i j}^{*}-q_{i j}\right)
$$

\section{Initial Conditions}

$$
t=0: \quad c_{i j}=q_{i j}=0
$$

Boundary Conditions for Section $j$

$$
z=0: \quad c_{i j}-\frac{D_{L_{j}}}{v_{j}} \frac{d c_{i j}}{d z}=c_{i j, 0}
$$

where $c_{i j, 0}$ is the inlet concentration of species $i$ in section $j$. $z=L_{j}$

For extract and raffinate nodes

$$
c_{i j}=c_{i j+1,0}
$$

For the eluent node

$$
c_{i j}=\frac{v_{\mathrm{I}}}{v_{\mathrm{IV}}} c_{i j+1,0}
$$

For the feed node

$$
c_{i j}=\frac{v_{\mathrm{III}}}{v_{\mathrm{II}}} c_{i j+1,0}-\frac{v_{F}}{v_{\mathrm{II}}} c_{i}^{F}
$$

and

$$
q_{i j}=q_{i j+1,0}
$$

\section{Global Balances}

Eluent node

$$
v_{\mathrm{I}}=v_{\mathrm{IV}}+v_{E}
$$

Extract node

$$
v_{\mathrm{II}}=v_{\mathrm{I}}-v_{X}
$$

Feed node

$$
v_{\text {III }}=v_{\text {II }}+v_{F}
$$

Raffinate node

$$
v_{\mathrm{IV}}=v_{\mathrm{III}}-v_{R}
$$

Multicomponent Adsorption Equilibrium Isotherm

$$
q_{A j}^{*}=f_{A}\left(c_{A j}, c_{B j}\right) \quad \text { and } \quad q_{B j}^{*}=f_{B}\left(c_{A j}, c_{B j}\right)
$$

where $i=A, B$ refers to the species in the mixture, and $j=\mathrm{I}$, II, III, IV is the section number.

\section{Model parameters}

The resulting model parameters, after introducing axial and time dimensionless variables, are presented below:

The ratio between solid and fluid volumes,

$$
\frac{1-\epsilon}{\epsilon}
$$

the ratio between fluid and solid velocities

$$
\gamma_{k}^{*}=\frac{v_{k}^{*}}{u_{s}} \text { for } \mathrm{SMB}, \quad \gamma_{j}=\frac{v_{j}}{u_{s}} \text { for } \mathrm{TMB}
$$

Peclet number

$$
P e_{k}=\frac{v_{k}^{*} L_{c}}{D_{L k}} \text { for SMB }, \quad P e_{j}=\frac{v_{j} L_{j}}{D_{L j}} \text { for } \mathrm{TMB}
$$

Number of mass transfer units

$$
\alpha_{k}=\frac{k L_{c}}{u_{s}}=k t^{*} \text { for SMB }, \quad \alpha_{j}=\frac{k L_{j}}{u_{s}} \text { for TMB. }
$$

Adsorption equilibrium parameters must be added to the list above.

\section{Simulation Results}

The chromatographic resolution of binapththol enantiomers was considered for simulation purposes. The chiral stationary phase used in this system is 3,5-dinitrobenzoyl phenylglycine bonded to silica gel, and a mixture of $72 / 28$ $(\mathrm{v} / \mathrm{v})$ heptane/isopropanol was used as eluent. The limit of solubility in this eluent is $3 \mathrm{~g} / \mathrm{L}$ of each enantiomer. The adsorption equilibrium isotherms, measured at $25^{\circ} \mathrm{C}$, are of bi-Langmuir type and were proposed by the Separex group (Nicoud and Seidel-Morgenstern, 1993; Nicoud, 1995)

$$
\begin{aligned}
& q_{A}^{*}=\frac{2.69 c_{A}}{1+0.0336 c_{A}+0.0466 c_{B}}+\frac{0.10 c_{A}}{1+c_{A}+3 c_{B}} \\
& q_{B}^{*}=\frac{3.73 c_{B}}{1+0.0336 c_{A}+0.0466 c_{B}}+\frac{0.30 c_{B}}{1+c_{A}+3 c_{B}}
\end{aligned}
$$




\begin{tabular}{lrl}
\hline \multicolumn{2}{c}{ TMB Operation Conditions } & \multicolumn{1}{c}{ Model Parameters } \\
\hline Feed concentration: & $2.9 \mathrm{~g} / \mathrm{L}$ each & Solid/fluid volumes, $(1-\epsilon) / \epsilon=1.5$ \\
Solid flow rate: & $11.15 \mathrm{~mL} / \mathrm{min}$ & Ratio between fluid and solid velocities: \\
Recycling flow rate: & $27.95 \mathrm{~mL} / \mathrm{min}$ & $\gamma_{\mathrm{I}}=6.65 ; \gamma_{\mathrm{II}}=4.23 ; \gamma_{\mathrm{III}}=4.72 ; \gamma_{\mathrm{IV}}=3.76$ \\
Eluent flow rate: & $21.45 \mathrm{~mL} / \mathrm{min}$ & Number of mass transfer units, $\alpha=36.0(k=0.1 \mathrm{~s}-1)$ \\
Extract flow rate: & $17.98 \mathrm{~mL} / \mathrm{min}$ & Peclet number, $P e=2,000$ \\
Feed flow rate: & $3.64 \mathrm{~mL} / \mathrm{min}$ & \\
Raffinate flow rate: & $7.11 \mathrm{~mL} / \mathrm{min}$ & \\
Columns: & & Section Length: $21.0 \mathrm{~cm}$ \\
Diameter: $2.6 \mathrm{~cm}$ & & \\
\hline
\end{tabular}

The operating conditions and model parameters used in the simulation for the TMB approach are presented in Table 2. Tables 3 and 4 present the equivalences in terms of flow rates and model parameters that have to be made for the SMB systems with different subdivisions of the bed. Note that for SMB systems, the internal flow rates in the four different sections are independent of the degree of subdivision of the bed and they are related to the TMB flow rates by the equivalences presented before. Three cases are analyzed for the SMB system: SMB4, constituted by four columns, one in each section; SMB8, with eight columns, two per section; and SMB12, with three columns per section. The length of each fixed-bed column in these cases was chosen by keeping constant the total length of each section. The value for the switch time interval was then evaluated keeping constant the ratio $L_{c} / t^{*}$, the simulated solid velocity. Also, the number of mass-transfer units per section is the same for the TMB and SMB cases and is evaluated for $k=0.1 \mathrm{~s}^{-1}$ (Table 4). Summarizing, all the SMB cases present the same operating conditions and model parameters at a section scale (equivalent to the TMB case), except for the degree of subdivision of the bed.

The cyclic steady-state behavior, characteristic of an SMB operation, is shown in Figures 3 and 4 for the case of an 8 -columns configuration (two columns per section). Figure 3 presents the concentration of the two enantiomers in extract (Figure $3 a$ ) and raffinate (Figure $3 b$ ) after cyclic steady state is reached (in this case, after ten full cycles). Extract and raffinate exhibit concentration profiles that are reproduced in the same way fraction after fraction. For the same case

Table 3. Equivalence Between TMB and SMB Flow Rates

\begin{tabular}{ccccc}
\hline & \multicolumn{2}{c}{ TMB } & \multicolumn{2}{c}{ SMB } \\
\hline Section & $Q_{i}$ & $\gamma_{j}$ & $Q_{i}^{*}$ & $\gamma_{i}^{*}$ \\
\hline I & 49.40 & 6.65 & 56.83 & 7.65 \\
II & 31.42 & 4.23 & 38.85 & 5.23 \\
III & 35.06 & 4.72 & 42.49 & 5.72 \\
IV & 27.95 & 3.76 & 35.38 & 4.76 \\
\hline
\end{tabular}

(SMB8), Figure 4 shows the evolution of the internal concentration profiles after cyclic steady state is reached during a switch time interval. Note that, since steady state is achieved, the concentration profiles at the end of a switch time interval are the same at the beginning of this interval, but they are
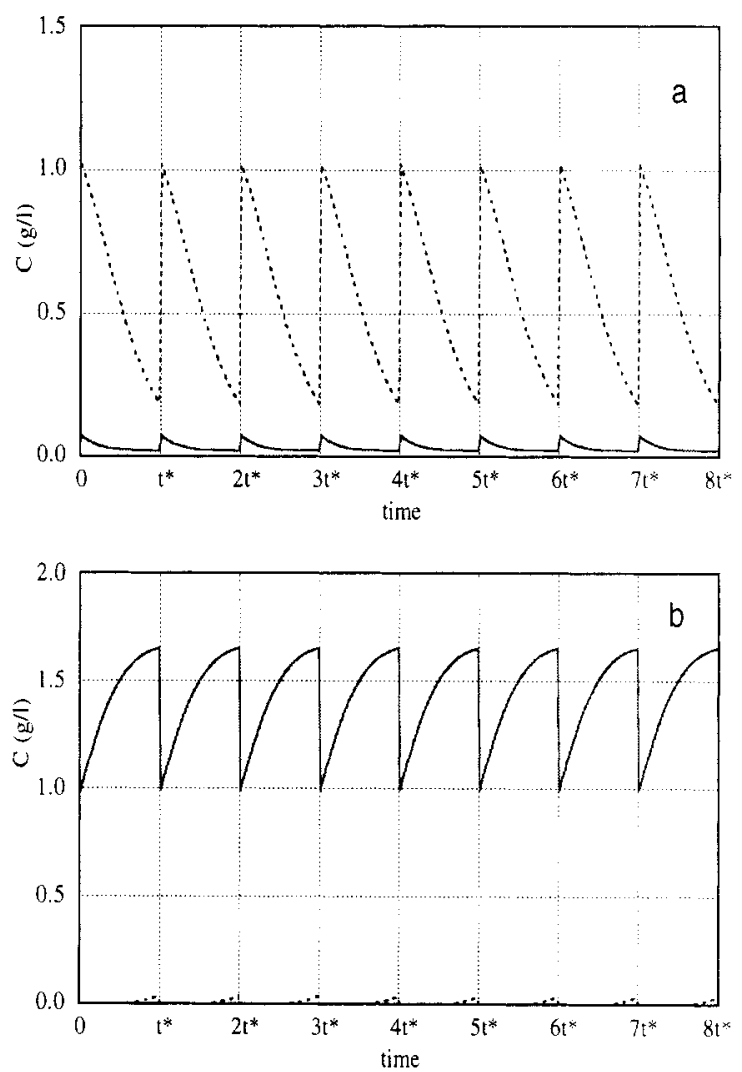

Figure 3. Concentration profiles in (a) the extract and (b) raffinate for SMBB at cyclic steady state and during a full cycle.

Dotted line is for the more retained component; solid line is for the less retained component.

Table 4. Equivalence Between the TMB and the SMB Approaches with Different Subdivision of the Bed

\begin{tabular}{ccccccccc}
\hline Case & $N_{s}$ & $\begin{array}{c}L_{c} \\
\mathrm{~cm}\end{array}$ & $\begin{array}{c}L_{j} \\
\mathrm{~cm}\end{array}$ & $\begin{array}{c}t^{*} \\
\min \end{array}$ & $\begin{array}{c}u_{s}=L_{c} / t^{*} \\
\mathrm{~cm} / \mathrm{min}\end{array}$ & $\alpha$ & $N_{s} \alpha$ & $P e$ \\
\hline TMB & - & - & 21 & - & 3.5 & 36 & 36 & 2,000 \\
SMB4 & 1 & 21 & 21 & 6 & 3.5 & 36 & 36 & 2,000 \\
SMB8 & 2 & 10.5 & 21 & 3 & 3.5 & 18 & 36 & 1,000 \\
SMB12 & 3 & 7 & 21 & 2 & 3.5 & 12 & 36 & 667 \\
\hline
\end{tabular}



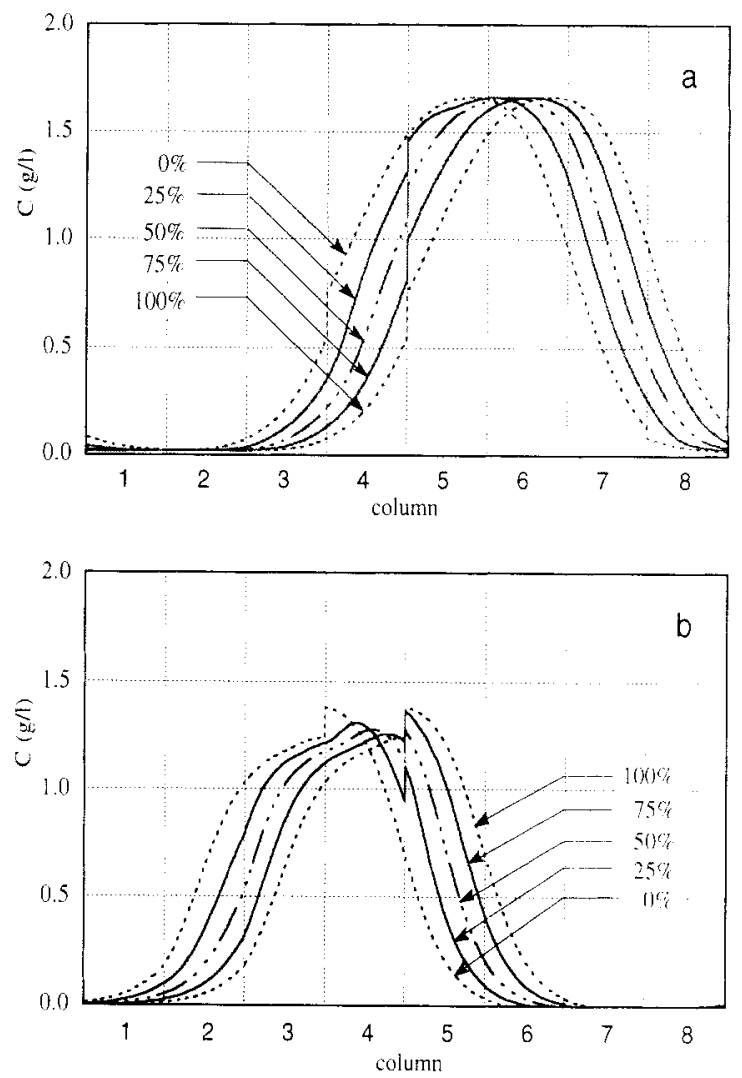

Figure 4. Cyclic steady-state internal concentration profiles during a switch time interval (fraction) for SMB8.

Profiles for the less retained component (4a) and for the more retained component ( $4 \mathrm{~b})$ at the beginning, $25 \%, 50 \%$. $75 \%$, and at the end of a switch time interval (eluent at the beginning of column 1; extract between columns 2 and 3 feed between columns 4 and 5 ; raffinate between columns 6 and 7 ).

advanced one column. Again, these profiles will be reproduced in the same way fraction after fraction and column after column.

Figures 5 and 6 show the influence of the degree of subdivision of the bed in the transient concentration of extract and raffinate, and make the comparison with the TMB approach. The behavior of the SMB is predicted in three ways: the exact transient evolution of concentration profiles, the average concentration evaluated at each switch time interval, and the instantaneous concentration evaluated between two successive switchings. These figures show the transient evolution during the first five cycles. Although the switch time interval depends on the degree of subdivision of the bed, the duration of a full cycle will be $24 \mathrm{~min}$ for all SMB cases. From these figures, it is clear that there are differences between SMB and TMB predictions, and that they are attenuated with the increase of the number of subdivisions. In fact, the similarity would be perfect if the adsorbent bed were divided into an infinite number of fixed-bed columns and using an infinitesimal switch time interval. This can be corroborated by noticing that the amplitude of variation of exact concentration is decreasing and approaching the TMB behavior, with the increase of the number of subsections.
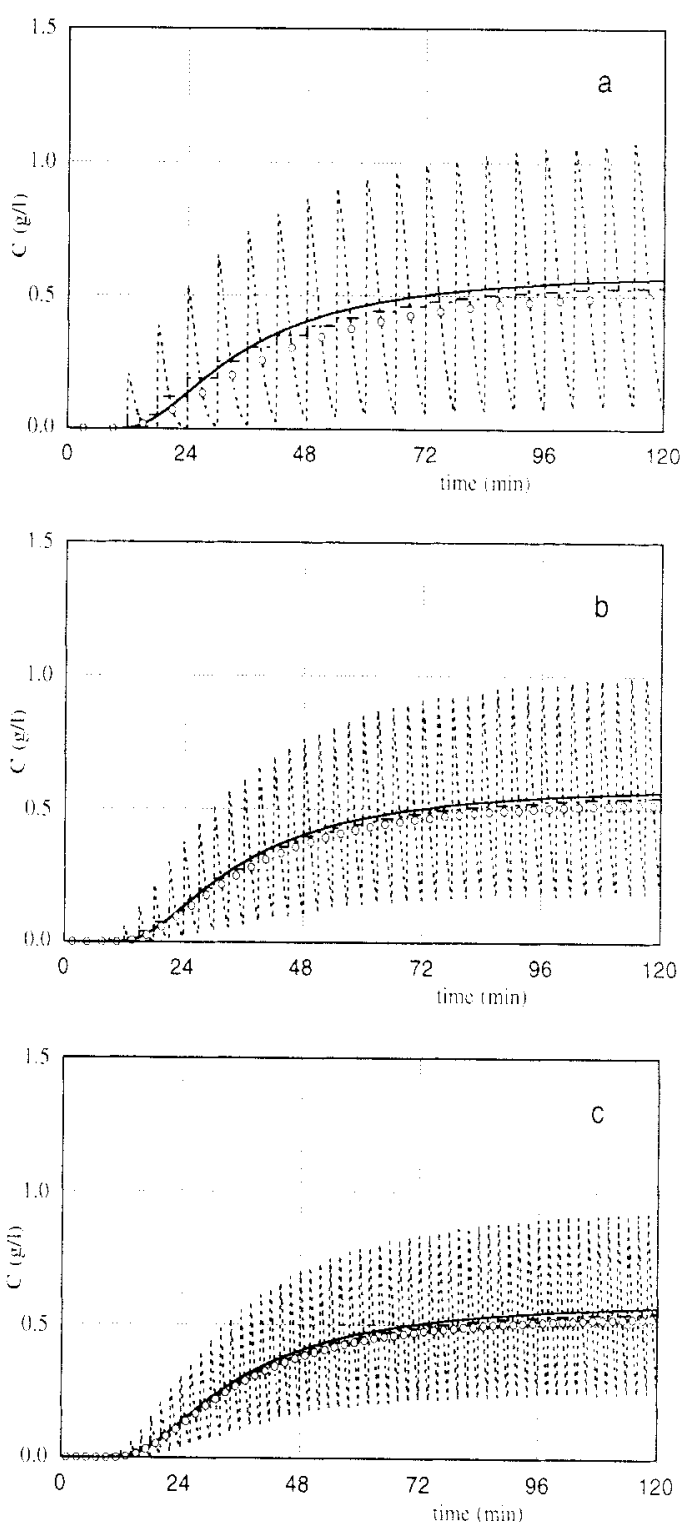

Figure 5. Transient evolution (first 5 cycles) of the concentration of the more retained component in the extract for (a) SMB4, (b) SMB8, and (c) SMB12.

The full line is the TMB approach; the dotted line is the SMB approach; step dotted line is the SMB approach with average concentration over a switch time interval; 000 is the SMB instantaneous concentration evaluated between switchings.

Figure 7 compares the steady-state internal concentration profiles evaluated between switchings for TMB and SMB cases. The major difference appears for the SMB4 case, while small deviations occur between SMB8 and SMB12 behaviors. Nevertheless, near the feed point, there is a permanent difference between TMB and all SMB cases. This is due to the fact that the internal flow rates in the TMB are smaller than in the SMB, leading to a small dilution of the feed stream (see Table 3 and mass balances for the feed node, Eqs. 5c and $12 \mathrm{c}$ ). As a consequence, near the feed inlet, TMB concentrations will be greater than in the SMB operation. The 

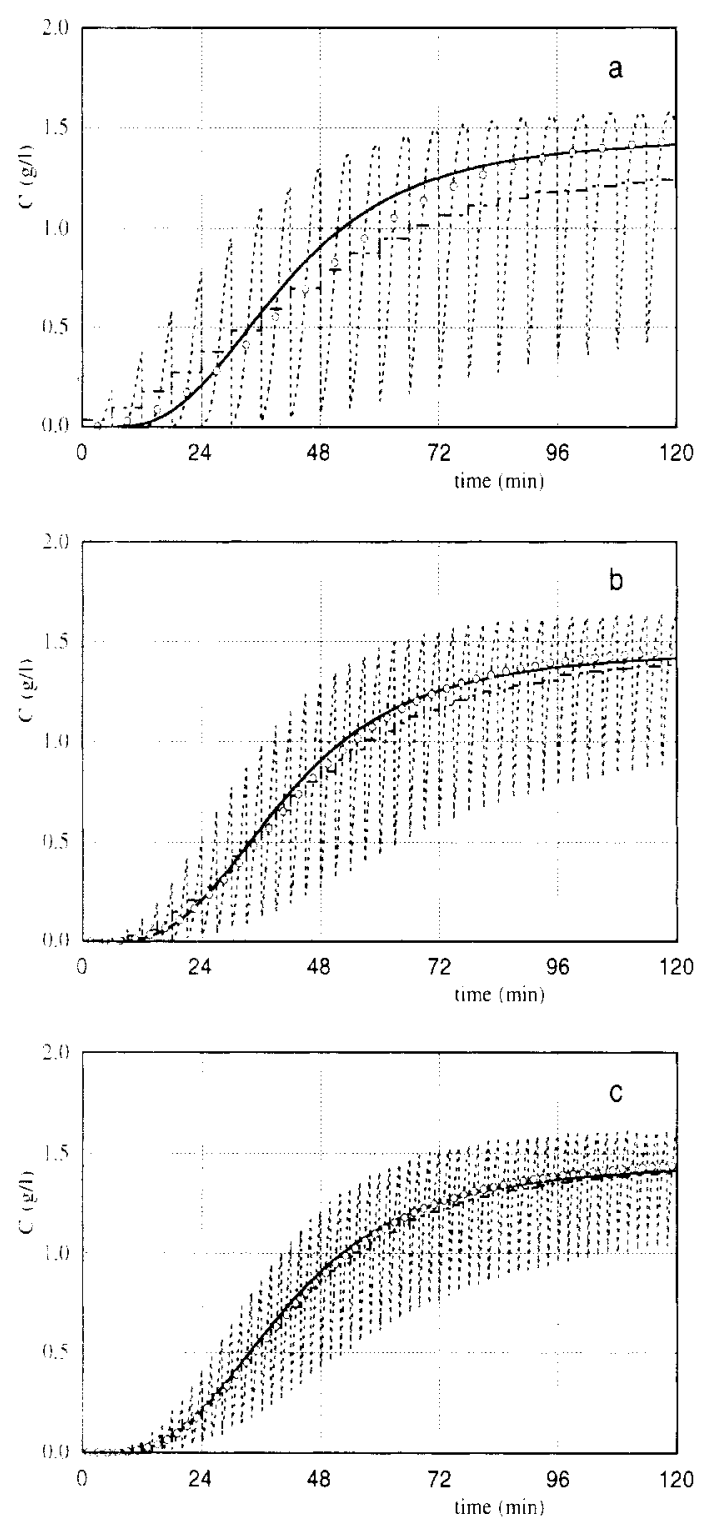

Figure 6. Transient evolution (first 5 cycles) of the concentration of the less retained component in the raffinate for (a) SMB4, (b) SMB8, and (c) SMB12.

The full line is the TMB approach; the dotted line is the SMB approach; the step dotted line is SMB approach with average concentration over a switch time interval; 000 is the SMB instantaneous concentration evaluated between switchings.

opposite will occur near the eluent point, although the differences will be insignificant if concentrations are near zero, as usually occurs when flow rates are well estimated.

For practical aims, the more important question may be what is the difference between the TMB and SMB performances and what is the influence of the degree of subdivision of the adsorbent bed. Table 5 shows the predictions obtained for extract and raffinate purities after steady state is reached. The raffinate and extract purities in SMB units with 4, 8 and 12 columns are increasing towards the one obtained in the equivalent TMB unit. An uncommon difference appears for
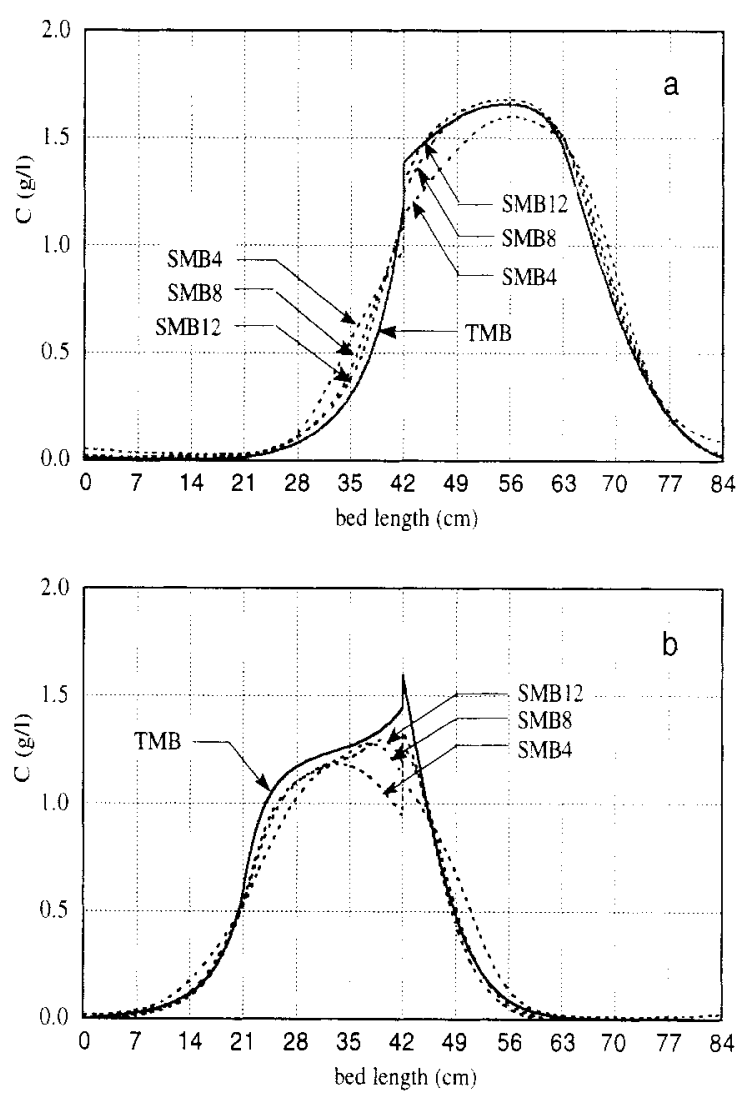

Figure 7. Steady-state internal concentration profiles in the TMB approach and SMB cases at half-time between switchings: (a) less retained component; (b) more retained component.

The full line is for TMB approach; the dotted line is for $S M B$ cases (eluent inlet $=0 \mathrm{~cm}$; extract outlet $=21 \mathrm{~cm}$; feed inlet $=42 \mathrm{~cm}$; raffinate outlet $=63 \mathrm{~cm}$ )

the SMB4 case. This can be easily explained, noticing that only in this case, the jump of one inlet or outlet line is done to a column that did not already perform the same function of the previous column (because they do not belong to the same section). In fact, the extract outlet will jump at the beginning of each switch time interval to the previous feed inlet, and the same will occur between raffinate and eluent. For the other SMB cases, the differences are not so significant, and a practical question remains: from an economic point of view, what is the optimum degree of the subdivision of an SMB system? The answer to this question will always depend on the difficulty of the separation and the product purity requirements, as was determined by Hidajat et al. (1986b) and, more recently, by Tondeur and Bailly (1993) and Bauer et al. (1996).

Table 5. Comparison Between Extract and Raffinate Purities in the TMB Approach and SMB Cases

\begin{tabular}{ccc}
\hline Case & $\begin{array}{c}\text { Extract } \\
\text { Purity }(\%)\end{array}$ & $\begin{array}{c}\text { Raffinate } \\
\text { Purity }(\%)\end{array}$ \\
\hline SMB4 & 89.7 & 95.3 \\
SMB8 & 95.9 & 98.7 \\
SMB12 & 96.8 & 99.1 \\
TMB & 97.7 & 99.3 \\
\hline
\end{tabular}


Table 6. Experimental SMB Operating Conditions for the Binaphthol System

\begin{tabular}{ll}
\hline \multicolumn{1}{c}{ Columns } & \multicolumn{1}{c}{ Flow Rates $(\mathrm{mL} / \mathrm{min})$} \\
\hline Diameter, $2.6 \mathrm{~cm}$ & Recycling: 35.38 \\
Length, $10.5 \mathrm{~cm}$ & Eluent: 21.45 \\
Number, 8 & Extract: 16.00 \\
Configuration, $2-2-2-2$ & Feed: 3.64 \\
Temperature, $25^{\circ} \mathrm{C}$ & Raffinate: 9.09 \\
Feed conc., $2.9 \mathrm{~g} / \mathrm{L}$ each & Switch time interval: $2.75 \mathrm{~min}$ \\
\hline
\end{tabular}

\section{Experimental Studies}

The chromatographic resolution of bi-naphthol enantiomers was implemented in an SMB pilot plant, LICOSEP
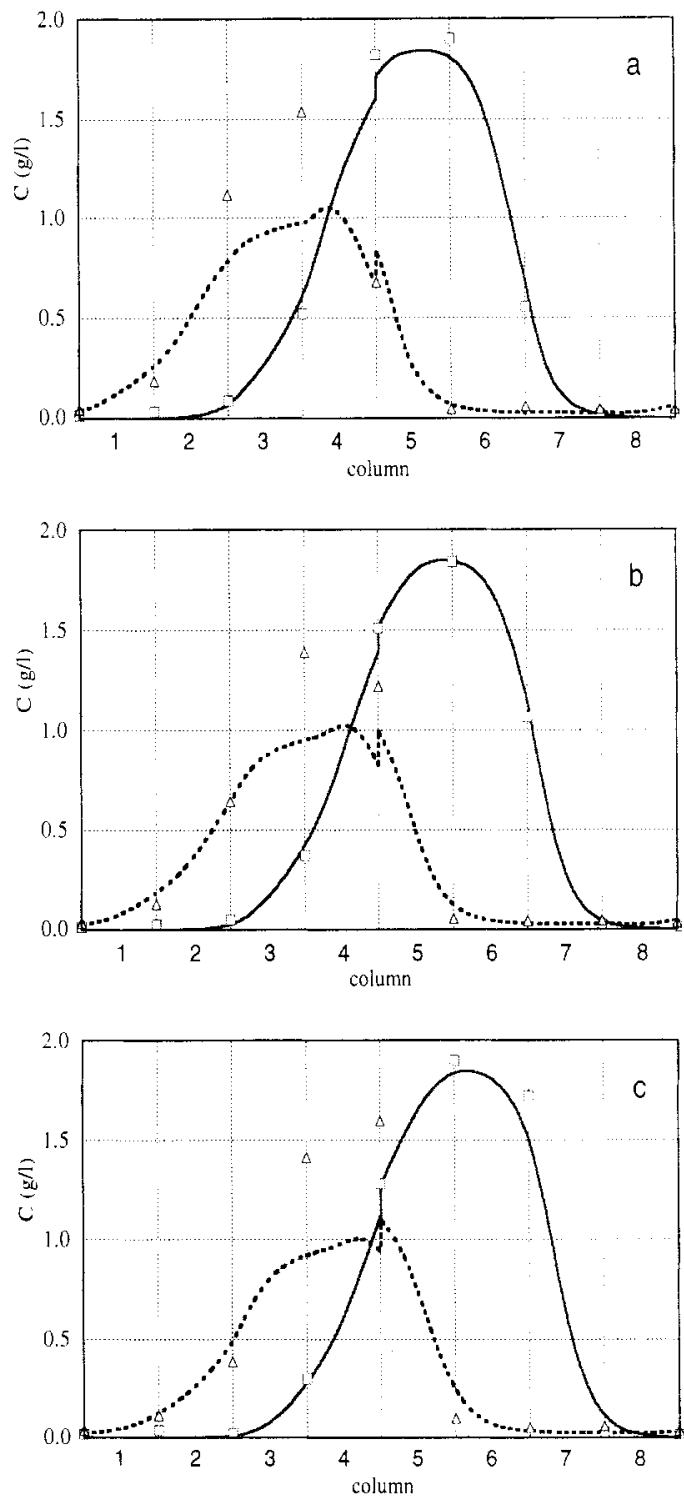

Figure 8. Experimental vs. simulated steady-state internal concentration profiles evaluated at (a) $25 \%$, (b) $50 \%$, and (c) $75 \%$ of a switch time interval.

Symbols represent experimental data; lines for simulation results; squares and full lines for the less retained component, triangles and dotted lines for the more retained component.
12-26, developed by Separex (now Novasep, Vandoeuvre-lésNancy, France) in cooperation with the Institut Français du Pétrole. The description of this system can be found elsewhere (Pais et al., 1997a). The experimental operating conditions are summarized in Table 6.

After cyclic steady state was achieved (more than 25 cycles), experimental internal concentration profiles were evaluated at different moments of a switch time interval. Simulations with the same operating conditions were carried out and the results are compared in Figure 8 . The experimental purities obtained were $93.0 \%$ for extract and $96.2 \%$ for raffinate, while the simulation predictions using the SMB8 model are 93.8 and $97.3 \%$, respectively. Figure 8 shows a reasonable agreement between experimental and simulation predictions, although some differences appear in the profile of the more retained component in the second section, which can be explained by some deviation of the internal flow rates that can lead to significant differences in the internal concentration profiles.

\section{Conclusions}

It is clear from this work that the prediction of the performance of an SMB operation, and therefore the flow rate optimization, can be done using the TMB approach, although small differences will appear between these two strategies of modeling. These differences will be more significant if a low degree of subdivision of the adsorbent bed is used, especially in the case of an SMB with only one column per section. For practical aims, the optimum degree of subdivision will depend on both the difficulty of the separation and the product purity requirements. Nevertheless, the SMB model will be always useful to characterize the cyclic behavior of the concentration profiles, as was experimentally shown in this work.

\section{Acknowledgments}

Financial support from the European Community under the BRITE-EURAM Programme (Contract No. BRE2-CT92-0337) is gratefully acknowledged. Thanks are also due to R.-M. Nicoud, J. Blehaut, F. Charton (Novasep), and J. Kinkel (Merck, Georg-SimonOhm Fachhochschule) for helpful discussions and preparation of the chiral packing.

\section{Notation}

$D_{L}=$ axial dispersion coefficient

$k=$ mass-transfer coefficient

$N_{s}=$ number of columns per section

$Q=$ volumetric liquid flow rate in a TMB

$Q^{*}=$ volumetric liquid flow rate in an SMB

$Q_{s}=$ solid flow rate

$q=$ average adsorbed phase concentration

$q^{*}=$ adsorbed concentration in equilibrium with fluid phase concentration

$V_{c}=$ column volume

$z=$ axial coordinate

$\alpha=$ number of mass-transfer units

$\gamma=$ ratio between fluid and solid velocities in a TMB, $\gamma_{j}=\nu_{j} / u_{s}$

$\gamma^{*}=$ ratio between fluid and solid velocities in an SMB, $\gamma_{k}^{*}=\nu_{k}^{*} / u_{s}$

$\epsilon=$ bed porosity

\section{Subscripts and superscripts}

$A=$ less retained component

$B=$ more retained component

$E=$ eluent 


$$
\begin{aligned}
F & =\text { feed } \\
R & =\text { raffinate } \\
X & =\text { extract } \\
i & =\text { component } \\
k & =\text { column }
\end{aligned}
$$

\section{Literature Cited}

Balannec, B., and G. Hotier, "From Batch Elution to Simulated Countercurrent Chromatography," Preparative and Production Scale Chromatography, G. Ganetsos and P. E. Barker, eds., Marcel Dekker, New York, p. 301 (1993).

Bauer, J., J. Priegnitz, A. Chandhok, and S. Wilcher, "UOP Sorbex Simulated Moving Bed Technology: The Effect of Bed Number on Simulated Moving Bed Performance," Int. Symp. on Preparative and Industrial Chromatography and Related Techniques, Basel (1996).

Broughton, D. B., and C. G. Gerhold, "Continuous Sorption Process Employing Fixed Bed of Sorbent and Moving Inlets and Outlets," U.S. Patent No. 2,985,589 (1961).

Cavoy, E., M.-F. Deltent, S. Lehoucq, and D. Miggiano, "In House Developed Simulated Moving Bed for Chiral Drug Separations: Design of the SMB System and Methodology," Int. Symp. on Preparative and Industrial Chromatography and Related Techniques, Basel (1996).

Charton, F., and R.-M. Nicoud, "Complete Design of a Simulated Moving Bed," J. Chromatog. A, 702, 97 (1995).

Ching, C. B., B. G. Lim, E. J. D. Lee, and S. C. Ng, "Preparative Resolution of Praziquantel Enantiomers by Simulated CounterCurrent Chromatography," J. Chromatog., 634, 215 (1993).

Chu, K. H., and M. A. Hashim, "Simulated Countercurrent Adsorption Processes: A Comparison of Modelling Strategies," Chem. Eng. J., 56, 59 (1995).

Dandekar. H. W., A. K. Chandhok, and J. K. Priegnitz, "Modeling and Simulation of SMB Technology for Pharmaceutical and Fine Chemical Applications," Proc. Int. Conf. on Fundamentals of Adsorption, M. D. LeVan, ed., Kluwer Academic Publishers, Boston, p. 243 (1996).

Francotte, E., and P. Richert, "Application of the Simulated Moving Bed Chromatography to Chiral Separations," Int. Symp. on Preparative and Industrial Chromatography and Related Techniques, Basel (1996).

Fuchs, G., R.-M. Nicoud, and M. Bailly, "Optical Isomers Purification with the Simulated Moving Bed Technology: Experimental and Theoretical Approaches," Proc. of 9th Int. Symp. on Preparative and Industrial Chromatography, M. Perrut, ed., Soc. Française de Chimie, Nancy, p. 395 (1992).

Gattuso, M. J., B. McCulloch, and J. W. Priegnitz, "UOP Sorbex Simulated Moving Bed Technology. A Cost Effective Route To Chiral Products," Symp. on Chiral Europe, (1994).

Gattuso, M. J., and S. Makino, "Simulated Moving Bed Technology: A Cost Effective Process for Enantiomeric Separations," Int. Symp. on Preparative and Industrial Chromatography and Related Techniques, Baden-Baden (1994).

Gattuso, M. J., B. McCulloch, D. W. House, and W. M. Baumann, "UOP Simulated Moving Bed Technology-The Preparation of Single Enantiomer Drugs," Chiral, Boston (1995).

Gattuso, M. J., B. McCulloch, D. W. House, W. M. Baumann, and K. Gottschall, "Simulated Moving Bed Technology-The Preparation of Single Enantiomer Drugs," Pharm. Tech. Europe, 8, 20 (1996).

Guest, D. W., "Evaluation of Simulated Moving Bed Chromatography for Pharmaceutical Process Development," J. Chromatog. A, 760, 159 (1997).

Hashimoto, K., S. Adachi, H. Noujima, and H. Maruyama, "Models for the Separation of Glucose/Fructose Mixture Using a Simulated Moving-Bed Adsorber," J. Chem. Eng. Japan, 16, 400 (1983).

Hassan, M. M., A. K. M. Shamsur Rahman, and K. F. Loughlin, "Modelling of Simulated Moving Bed Adsorption System: A More Precise Approach," Sep. Tech., 5, 77 (1995).

Hidajat, K., C. B. Ching, and D. M. Ruthven, "Numerical Simulation of a Semi-Continuous Counter-Current Adsorption Unit for Fructose-Glucose Separation," Chem. Eng. J., 33, B55 (1986a).
Hidajat, K., C. B. Ching, and D. M. Ruthven, "Simulated CounterCurrent Adsorption Processes: a Theoretical Analysis of the Effect of Subdividing the Adsorbent Bed," Chem. Eng. Sci., 41, 2953 (1986b).

Hotier, G., "Physically Meaningful Modeling of the 3-Zone and 4Zone Simulated Moving Bed Processes," AIChE J., 42, 154 (1996).

Lim, B. G., and C. B. Ching, "Modelling Studies on the Transient and Steady State Behaviour of a Simulated Counter-Current Chromatographic System," Sep. Tech., 6, 29 (1996).

McCulloch, B., J. Priegnitz, and A. Chandhok, "Simulated Moving Bed Adsorption as a Preparative Tool," HPLC'94-Int. Symp. on Column Liquid Chromatography, Minneapolis (1994).

Negawa, M., and F. Shoji, "Optical Resolution by Simulated MovingBed Adsorption Technology," J. Chromatog., 590, 113 (1992).

Nicoud, R.-M., G. Fuchs, E. Kusters, F. Antia, R. Reuille, and E. Schmid, "Preparative Scale Enantioseparation of a Chiral Epoxide-A Comparison of Liquid Chromatography and Simulated Moving.Bed Adsorption Technology," Int. Symp. on Chiral Discrimination, Tubigen (1992).

Nicoud, R.-M., Simulated Moving Bed: Basics and Applications, Int. National Polytechnique de Lorraine, Nancy (1993).

Nicoud, R.-M., and A. Seidel-Morgenstern, "Adsorption Isotherms: Experimental Determination and Application to Preparative Chromatography," Simulated Moving Bed: Basics and Applications, R.-M. Nicoud, ed., Inst. National Polytechnique de Lorraine, Nancy, p. 4 (1993).

Nicoud, R.-M., Personal Communication (1995).

Nicoud, R.-M., Recent Advances in Industrial Chromatographic Processes, Nancy (1997).

Pais, L. S., J. M. Loureiro, and A. E. Rodrigues, "Separation of 1,1'Bi-2-Naphthol Enantiomers by Continuous Chromatography in Simulated Moving Bed," Chem. Eng. Sci., 52, 245 (1997a).

Pais, L. S., J. M. Loureiro, and A. E. Rodrigues, "Modeling, Simulation and Operation of a Simulated Moving Bed for Continuous Chromatographic Separation of 1,1'-Bi-2-Naphthol Enantiomers," J. Chromatog. A, 769, 25 (1997b).

Ruthven, D. M., and C. B. Ching, "Counter-Current and Simulated Counter-Current Adsorption Separation Processes," Chem. Eng. Sci., 44, 1011 (1989).

Schulte, M., R. Ditz, R. M. Devant, J. N. Kinkel, and F. Charton, "Comparison of the Specific Productivity of Different Chiral Stationary Phases Used for Simulated Moving Bed Chromatography," Int. Symp. on Preparative and Industrial Chromatography and Related Techniques, Basel (1996).

Storti, G., M. Masi, R. Paludetto, M. Mordidelli, and S. Carrà, "Adsorption Separation Processes: Countercurrent and Simulated Countercurrent Operations," Comput. Chem. Eng., 12, 475 (1988).

Storti, G., M. Masi, S. Carrà, and M. Morbidelli, "Simulated Moving Bed Adsorption Separation Units with a Small Number of Ports," Proc. Int. Conf. on Fundamentals of Adsorption, Southofen, p. 845 (1989a).

Storti, G., M. Masi, and M. Morbidelli, "On Countrecurrent Adsorption Separation Processes," Adsorption: Science and Technology, A. E. Rodrigues et al., eds., Kluwer Academic Publishers, p. 357 (1989b).

Tondeur, D., and M. Bailly, "Simulated Countercurrent, Fixed-Bed and Column Switching Schemes," Simulated Moving Bed: Basics and Applications, R.-M. Nicoud, ed., Institut National Polytechnique de Lorraine, Nancy, p. 97 (1993).

Yun, T., G. Zhong, and G. Guiochon, "Simulated Moving Bed Under Linear Conditions: Experimental vs. Calculated Results," AIChE J., 43, 935 (1997).

Zhong, G., and G. Guiochon, "Analytical Solution for the Linear Ideal Model of Simulated Moving Bed Chromatography," Chem. Eng. Sci., 51, 4307 (1996).

Zhong, G., and G. Guichon, "Simulated Moving Bed Chromatography: Effects of Axial Dispersion and Mass Transfer under Linear Conditions," Chem. Eng. Sci., 52, 3117 (1997).

Manuscript received Aug. 11, 1997, and revision received Oct. 23, 1997 